\title{
Zinc oxide doping effects in polarization switching of lithium niobate
}

\author{
L.-H. Peng, ${ }^{\text {a) }}$ Y.-C. Zhang, and Y.-C. Lin \\ Department of Electrical Engineering and Institute of Electro-Optical Engineering, \\ National Taiwan University, Taipei, Taiwan, Republic of China
}

(Received 21 June 2000; accepted for publication 2 November 2000)

\begin{abstract}
We report a pulsed-field analysis on the $180^{\circ}$ domain reversal process in $Z$-cut congruent grown lithium niobate $\left(\mathrm{LiNbO}_{3}\right)$ doped with zinc oxide at concentration $C_{\mathrm{ZnO}}>5 \mathrm{~mol} \%$. The polarization switching field is found to decrease with the $\mathrm{ZnO}$ doping with a threshold $\left(E_{\mathrm{th}}\right)$ and internal $\left(E_{\mathrm{int}}\right)$ field as low as 2.5 and $0.5 \mathrm{kV} / \mathrm{mm}$, respectively, resultant on $8 \mathrm{~mol} \% \mathrm{ZnO}$ doped $\mathrm{LiNbO}_{3}$. The substantial decrease of $E_{\mathrm{th}}$ and $E_{\mathrm{int}}$ is ascribed to the suppression of nonstoichiometric point defects by the substitution of $\mathrm{Zn}^{2+}$ ions in the lattice site. (C) 2001 American Institute of Physics.
\end{abstract}

[DOI: $10.1063 / 1.1336815$ ]

Recent development of quasiphase-matching (QPM) techniques ${ }^{1,2}$ has greatly revived the research activities in nonlinear optics for wavelength conversion ${ }^{3}$ and high speed optical signal processing. ${ }^{4}$ Such success is ascribed to the realization of periodically poled lithium niobate (PPLN), ${ }^{5}$ lithium tantalate (PPLT), ${ }^{6}$ potassium titanyl phosphate, ${ }^{7}$ and more recently the commercialization of these materials. Although much attention has been focused on the applications of QPM structures, little has been known to the dynamics of the polarization switching process. Difficulties in making fine PPLN and PPLT structures are due to the high switching field $(>22 \mathrm{kV} / \mathrm{mm})$ induced domain-broadening effects. ${ }^{8}$ Consideration also has been given to the large internal field $(2.5-5.0 \mathrm{kV} / \mathrm{mm})$ that causes axial anisotropy in the poling process. ${ }^{9}$ Therefore, one must resort to sophisticated techniques such as backswitching that utilizes the nucleation and pinning process at various poling stages to realize fine QPM structures. ${ }^{10,11}$

On the other hand, it is suggested that the high switching and large internal fields are originated from the nonstoichiometric defects associated with crystal growth from the congruent melt. ${ }^{9}$ Switching field reduction by a factor of 5 and 13, respectively, has been reported on near-stoichiometric $\mathrm{LiNbO}_{3}{ }^{12}$ and $\mathrm{LiTaO}_{3} \cdot{ }^{13}$ Good control of stoichiometry can also reduce the internal field down to $\sim 0.1 \mathrm{kV} / \mathrm{mm}$. For $\mathrm{LiNbO}_{3}$, this field reduction occurs with enhanced photorefractive (also known as optical damage) effects. ${ }^{14}$ Such photoinduced changes in the refractive indices can lead to substantial change in the QPM condition and loss of the conversion efficiency. ${ }^{15,16}$ For practical nonlinear application of stoichiometric $\mathrm{LiNbO}_{3}$, it is found necessary to dope the crystal with magnesium oxide $(\mathrm{MgO})$ to $\sim 1.8 \mathrm{~mol} \%$ to raise the optical damage resistance. ${ }^{17}$

As for the commonly used congruent-grown $\mathrm{LiNbO}_{3}$, the switching field reduction can be activated by adding 5 $\mathrm{mol} \%$ of $\mathrm{MgO}$ in the crystal. ${ }^{18-20}$ The operation of optical parametric oscillators on PPMgLN has revealed superior optical damage resistance to that on conventional PPLN. ${ }^{21}$ In addition, $\mathrm{LiNbO}_{3}$ is known to support other kinds of optical damage resistant impurities such as zinc oxide $(\mathrm{ZnO})$ and

${ }^{a)}$ Electronic mail: peng@cc.ee.ntu.edu.tw indium oxide ( $\mathrm{InO}){ }^{22}$ In this letter we report the use of transient current analysis to study the polarization switching process on $Z$-cut congruent-grown $\mathrm{LiNbO}_{3}$ doped with $\mathrm{ZnO}$ $\left(\mathrm{ZnO}: \mathrm{LiNbO}_{3}\right)$. The polarization switching rate and averaged peak switching current are found to increase with the $\mathrm{ZnO}$ doping in the crystal. By increasing the $\mathrm{ZnO}$ doping level to $8 \mathrm{~mol} \%$, significant decrease of the threshold and internal field down to 2.5 and $0.5 \mathrm{kV} / \mathrm{mm}$, respectively, can be realized. The substantial field reduction is ascribed to the suppression of nonstoichiometric point defects by the substitution of $\mathrm{Zn}^{2+}$ ions in the lattice site.

The Z-cut, 500- $\mu$ m-thick, double-side polished $\mathrm{ZnO}: \mathrm{LiNbO}_{3}$ substrates were obtained from Casix, China. The samples were diced into $1 \mathrm{~cm} \times 1 \mathrm{~cm}$ squares and had a patterned area of $\sim 10 \mathrm{~mm}^{2}$ contacted to the lithium chloride liquid electrode. The $\mathrm{ZnO}$ doping level investigated in this study was varied from 5 to $8 \mathrm{~mol} \%$. For pulsed-field poling of $\mathrm{LiNbO}_{3}$, a high voltage power supply made from IRCO (modified model C12K-20 for $12 \mathrm{kV}$ and $2 \mathrm{~mA}$ output) was used. The experimental set up was similar to that originally designed by Myers et al. ${ }^{23}$ in which the transient current flown through the $\mathrm{LiNbO}_{3}$ substrate was measured as the voltage drop across a series resistor. In order to stabilize the domain reversal process, a fast turn-on rectifying diode was put in series with the poling apparatus such that relaxation of the inverted domain can be inhibited at the termination of the pulsed field.

Shown in Fig. 1 is the field dependence of the switching current on $8 \mathrm{~mol} \% \mathrm{ZnO}: \mathrm{LiNbO}_{3}$ in the (a) forward and (b) reverse poling, respectively. Here an applied field $(E)$ as low as $3 \mathrm{kV} / \mathrm{mm}$ is sufficient to initiate the $180^{\circ}$ domain reversal process, whereas in the undoped case it has to be larger than $22 \mathrm{kV} / \mathrm{mm} .{ }^{9,23}$ A close examination of Fig. 1 also reveals the occurrence of Barkhausen spikes and non-vanishing ohmic current in the waveforms. ${ }^{18}$ The reappearance of compressed Barkhausen spikes in the successive forward and reverse poling signifies a reversible process of fusion ${ }^{24}$ and pinning ${ }^{25}$ of the lateral domain motion by the localized defects. These phenomena have been consistently observed, for example, in the domain reversal of Rochelle salt ${ }^{26}$ and $\mathrm{MgO}: \mathrm{LiNbO}_{3} .{ }^{18}$

The details of the $\mathrm{ZnO}$ doping effects on the polarization switching are further illustrated in Fig. 2 and vertically 

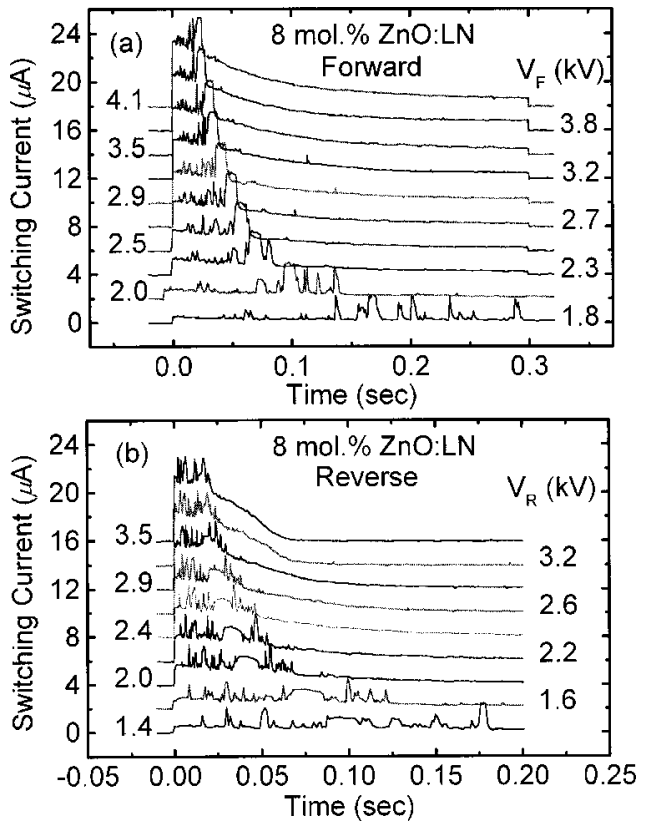

FIG. 1. Wave forms of the switching current during (a) forward and (b) reverse poling on a $8 \mathrm{~mol} \% \mathrm{ZnO}: \mathrm{LiNbO}_{3}$ crystal at various switching field.

shifted for comparison. We first note an increase of the averaged peak switching current with the $\mathrm{ZnO}$ doping. Since the switching current measures the exchange rate of the spontaneous polarization $\left(P_{s}\right)$, an increase in the switching current suggests a faster switching rate provided the variation of $P_{s}$ with $\mathrm{ZnO}$ doping is negligible. We note, within a variation of $\pm 6 \%$, the $P_{s}$ has been found insensitive to the nonstoichiometry in $\mathrm{LiNbO}_{3},{ }^{12} \mathrm{LiTaO}_{3},{ }^{13}$ and independent of the doping level (e.g., $\mathrm{MgO}^{18}$ and hydrogen ${ }^{12}$ in the crystal.

In support of this analysis, we explore in Fig. 3 the switching rate $\left(1 / t_{s}\right)$ dependence on the $\mathrm{ZnO}$ doping at a concentration of (a) 8 and (b) $5 \mathrm{~mol} \%$, respectively. Referred to Fig. 3, an increase of $1 / t_{s}$ with the $\mathrm{ZnO}$ doping can be clearly resolved. Moreover, we can infer from Fig. 3 a linear dependence of $1 / t_{s}$ on $E$. This phenomenon has been known to characterize a sidewise motion of the $180^{\circ}$ domain wall of Rochelle salt, ${ }^{26}$ gadolinium molybdate, ${ }^{27}$ and barium titanate $\left(\mathrm{BaTiO}_{3}\right)^{28}$ in the high-field regime. In comparison, the switching rate of $\mathrm{BaTiO}_{3}$ in the low-field regime is known to follow an exponential dependence. ${ }^{28}$ This unique linear dependence has thus enabled us to take advantage of a recently proposed mobility model ${ }^{29}$ to analyze the lateral domain motion of $\mathrm{ZnO}: \mathrm{LiNbO}_{3}$. In this model analysis, fast

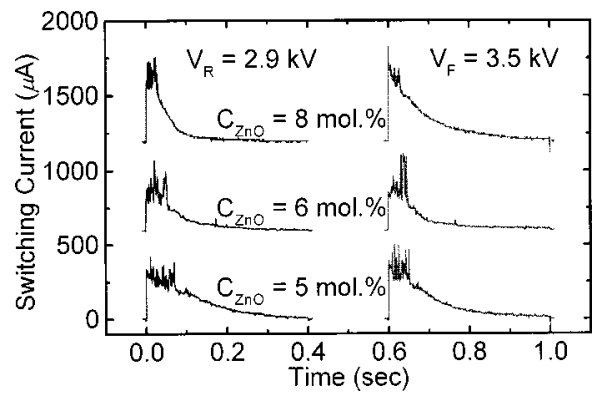

FIG. 2. Switching current on $\mathrm{ZnO}: \mathrm{LiNbO}_{3}$ at a doping level of 5, 6, and 8 mol \% with a forward and reverse poling voltage of 3.5 and $2.9 \mathrm{kV}$.

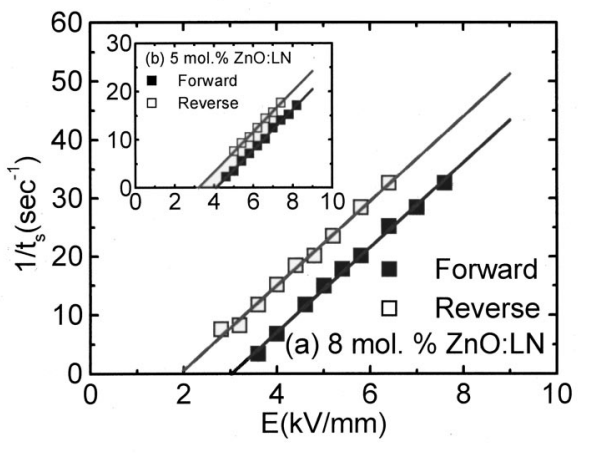

FIG. 3. Dependence of the polarization switching rate ( $\left.1 / t_{s}\right)$ on (a) 8 and (b) $5 \mathrm{~mol} \% \mathrm{ZnO}: \mathrm{LiNbO}_{3}$ in forward and reverse poling directions.

nucleation occurs preferentially in the crystal $c$ axis along the existing $180^{\circ}$ domain boundary, and serves to propagate the boundary in a sidewise direction. The apparent sidewise velocity $\left(v_{s}\right)$ of the $180^{\circ} \mathrm{LiNbO}_{3}$ domain motion in the highfield regime can be characterized by $v_{s}=\mu_{s}\left[E-\left(E_{\text {th }}\right.\right.$ $\left.\left.\pm E_{\text {int }}\right)\right]$. Here we use an internal field $E_{\text {int }}$ to signify the axial anisotropy, $\mu_{s}$ the lateral mobility, and $\left(E_{\mathrm{th}} \pm E_{\text {int }}\right)$ switching field in the forward $(+)$ and reverse (-) poling direction. $E_{\mathrm{th}}=18.74$ and $E_{\mathrm{int}}=2.37 \mathrm{kV} / \mathrm{mm}$ have thus been identified in undoped $\mathrm{LiNbO}_{3}{ }^{29}$ that agrees with a recent publication using the exponential fitting procedure. ${ }^{9}$ This analysis also enables us to make a decisive measure of $E_{\text {int }}$ and $E_{\text {th }}$ in $\mathrm{ZnO}: \mathrm{LiNbO}_{3}$ as shown in Fig. 4. Here we note that a significant decrease of $E_{\text {th }}$ and $E_{\text {int }}$ down to 2.5 and 0.5 $\mathrm{kV} / \mathrm{mm}$, respectively, can be realized on $8 \mathrm{~mol} \%$ $\mathrm{ZnO}: \mathrm{LiNbO}_{3}$.

The dramatic decrease of switching field indeed bears close relation to the $\mathrm{ZnO}$ doping effects on the crystal structure. Recent investigation on the electro-optical properties of $\mathrm{ZnO}: \mathrm{LiNbO}_{3}$ has suggested a compensation mechanism of the $\mathrm{Zn}^{2+}$ ions to the Li vacancy $\left(\mathrm{V}_{\mathrm{Li}}\right)$ and $\mathrm{Nb}$ antisite $\left(\mathrm{Nb}_{\mathrm{Li}}\right)$ defects. ${ }^{30}$ This mechanism is very similar to the structure effects caused by the $\mathrm{MgO}$ doping in the congruent-grown ${ }^{31}$ and stoichiometric ${ }^{32} \mathrm{LiNbO}_{3}$. With an increase of $\mathrm{Zn}(\mathrm{Mg})$ doping, the $\mathrm{Zn}(\mathrm{Mg})$ will initially replace the $\mathrm{Nb}_{\mathrm{Li}}$ and decrease the $\mathrm{V}_{\mathrm{Li}}$ defects in $\mathrm{LiNbO}_{3}$. It is concluded that up to a concentration of $6.4 \mathrm{~mol} \%$, the $\mathrm{Zn}^{2+}$ ions are localized at the Li site; whereas in a higher concentration $(>7.6 \mathrm{~mol} \%)$, the $\mathrm{Zn}^{2+}$ are partially incorporated at the $\mathrm{Nb}$ site. ${ }^{30}$ The action of high $\mathrm{Zn}$ doping thus results in (i) a substantial reduction of the nonstoichiometric point defects of $\mathrm{V}_{\mathrm{Li}}$ and $\mathrm{Nb}_{\mathrm{Li}}$, and (ii) an increase of the lattice constant $(a, c)$ due to the substitution of larger $\mathrm{Zn}^{2+}$ ions in the lattice site. The sig-

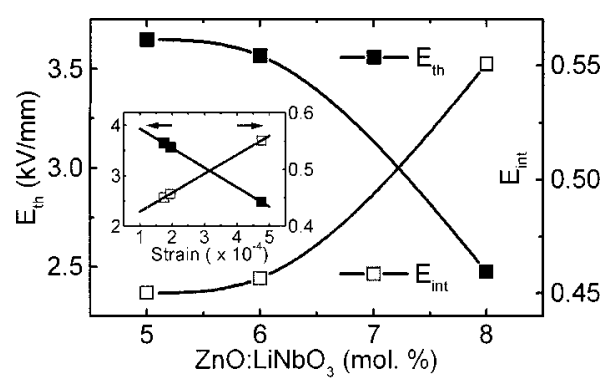

FIG. 4. Doping effects on the threshold $\left(E_{\mathrm{th}}\right)$ and internal $\left(E_{\text {int }}\right)$ field in the polarization switching of $\mathrm{ZnO}: \mathrm{LiNbO}_{3}$. 


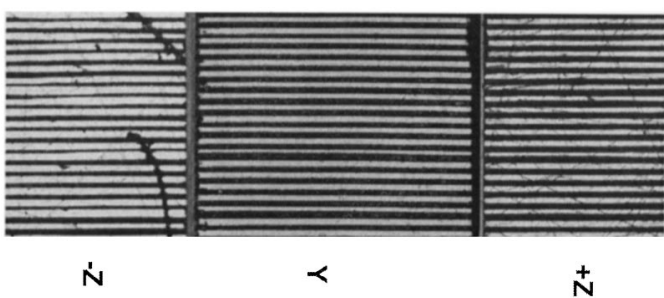

FIG. 5. Micrograph of ZnO:PPLN forward poled at $5 \mathrm{kV} / \mathrm{mm}$.

nificant decrease of $E_{\text {th }}$ and $E_{\text {int }}$ is therefore ascribed to the effective suppression of nonstoichiometric point defects by the substitution of $\mathrm{Zn}$ into the lattice site. Moreover, when the $\mathrm{ZnO}$ doping effects on the dilation of the lattice constant $a$ are transformed into the lattice tensile strain $\epsilon$, a linear dependence of $E_{\text {int }}$ and $E_{\mathrm{th}}$ on $\epsilon$ can be seen in the inset of Fig. 4. This observation indicates that the residual small $E_{\text {int }}$ in the highly doped $\mathrm{LiNbO}_{3}$ is related the strain induced piezoelectric effects in the crystal. ${ }^{33} \mathrm{~A}$ detailed analysis on the piezoelectric effects will be presented in a forthcoming publication.

Last but not the least, the introduction of high $\mathrm{ZnO}$ doping in congruent-grown $\mathrm{LiNbO}_{3}$ not only has realized itself as an optical damage-resistant crystal but also a promising candidate for making low field poled QPM structures. Shown in Fig. 5 is one such example on $5 \mathrm{~mol} \% \mathrm{ZnO}: \mathrm{LiNbO}_{3}$ forward poled at a low pulsed field of $5 \mathrm{kV} / \mathrm{mm}$. Good control of a periodicity of $20 \mu \mathrm{m}$ with a $50 \%$ duty cycle, and high aspect ratio over the $3 \mathrm{~mm}$ sample length and $500-\mu \mathrm{m}-$ thick substrate has thus been realized.

In summary, we report the $\mathrm{ZnO}$ doping effects on the polarization switching process in $Z$-cut congruent grown $\mathrm{LiNbO}_{3}$. Significant decrease of $E_{\text {th }}$ and $E_{\text {int }}$ down to 2.5 and $0.5 \mathrm{kV} / \mathrm{mm}$, respectively, can be realized on $8 \mathrm{~mol} \%$ $\mathrm{ZnO}: \mathrm{LiNbO}_{3}$. These observations are attributed to the suppression of nonstoichiometric point defects by the substitution of $\mathrm{Zn}^{2+}$ in the lattice site.

The authors wish to acknowledge technical support from the Integrated Optics and Solid State Laboratories at N. T. U. E. E. This research was supported by the National Science Council, Grant Nos. 89-2115-E-002-015 and 023.
${ }^{1}$ J. A. Armstrong, N. Bloembergen, J. Ducuing, and P. S. Pershan, Phys. Rev. 127, 1918 (1962).

${ }^{2}$ M. Houe and P. D. Townsend, J. Phys. D 28, 1747 (1995).

${ }^{3}$ P. E. Powers, T. J. Kulp, and S. E. Bisson, Opt. Lett. 23, 159 (1998).

${ }^{4}$ M. Arbore, A. Galvanauskas, D. Harter, M. Chou, and M. Fejer, Opt. Lett. 22, 1341 (1997).

${ }^{5}$ Y. Yamada, N. Nada, M. Saitoh, and K. Watanabe, Appl. Phys. Lett. 62, 435 (1993).

${ }^{6}$ K. Mizuuchi, K. Yamamota, and M. Kato, Appl. Phys. Lett. 70, 1201 (1997).

${ }^{7}$ H. Karlsson, F. Laurell, and L. K. Cheng, Appl. Phys. Lett. 74, 1519 (1999).

${ }^{8}$ G. Rosenman, Kh. Garb, A. Skliar, M. Oron, D. Eger, and M. Katz, Appl. Phys. Lett. 73, 865 (1998).

${ }^{9}$ V. Gopalan, T. E. Mitchell, and K. E. Sicakfus, Solid State Commun. 109, 111 (1999).

${ }^{10}$ R. G. Batchko, V. Y. Shur, M. M. Fejer, and R. L. Byer, Appl. Phys. Lett. 75, 1673 (1999).

${ }^{11}$ V. Ya. Shur, E. L. Rumyantsev, E. V. Nikolaeva, E. I. Shishkin, D. V. Fursov, R. G. Batchko, L. A. Eyres, M. M. Fejer, and R. L. Byer, Appl. Phys. Lett. 76, 143 (2000).

${ }^{12}$ V. Gopalan, T. E. Mitchell, Y. Furukawa, and K. Kitamura, Appl. Phys. Lett. 72, 1981 (1998).

${ }^{13}$ K. Kitamura, Y. Furukawa, K. Niwa, V. Gopalan, and T. E. Mitchell, Appl. Phys. Lett. 73, 3073 (1998).

${ }^{14}$ K. Kitamura, Y. Furukawa, Y. Ji, M. Zgonik, C. Medrano, G. Montemezzani, and P. Gunter, J. Appl. Phys. 82, 1006 (1997).

${ }^{15}$ D. Eger, M. A. Arbor, M. M. Fejer, and M. L. Bortz, J. Appl. Phys. 82, 998 (1998).

${ }^{16}$ C. Q. Xu, H. Okayama, and Y. Ogawa, J. Appl. Phys. 87, 3203 (2000).

${ }^{17}$ K. Niwa, Y. Furukawa, S. Takekawa, and K. Kitamura, J. Cryst. Growth 208, $493(2000)$

${ }^{18}$ A. Kuroda, S. Kurimura, and Y. Uesu, Appl. Phys. Lett. 69, 1565 (1996).

${ }^{19}$ A. Harada and Y. Nihei, Appl. Phys. Lett. 69, 2629 (1996).

${ }^{20}$ K. Mizuuchi, K. Yamamoto, and M. Kato, Electron. Lett. 32, 2091 (1996).

${ }^{21}$ M. Nakamura, M. Sugihara, M. Kotoh, H. Taniguchi, and K. Tadatomo, Jpn. J. Appl. Phys., Part 2 38, L1234 (1999).

${ }^{22}$ T. Volk, N. Rubinina, and M. Wöhlecke, J. Opt. Soc. Am. B 11, 1681 (1994).

${ }^{23}$ L. E. Myers, R. C. Eckardt, M. M. Fejer, R. L. Byer, W. R. Bosenberg, and J. W. Pierce, J. Opt. Soc. Am. B 12, 2102 (1995).

${ }^{24}$ A. G. Chynoweth, Phys. Rev. 110, 1316 (1958).

${ }^{25}$ T. J. Yang, V. Gopalan, P. J. Swart, and U. Mohideen, Phys. Rev. Lett. 82, 4106 (1999).

${ }^{26}$ T. Mitsui and J. Furuichi, Phys. Rev. 95, 558 (1954).

${ }^{27}$ R. B. Flippen, J. Appl. Phys. 46, 1068 (1975).

${ }^{28}$ H. L. Stadler and P. J. Zachmanidis, J. Appl. Phys. 34, 3255 (1963).

${ }^{29}$ L.-H. Peng, Y.-C. Fang, and Y.-C. Lin, Appl. Phys. Lett. 74, 2070 (1999).

${ }^{30}$ F. Abdi, M. Aillerie, M. Fontana, P. Bourson, T. Volk, B. Maximov, S. Sulyanov, N. Rubinina, and M. Wöhlecke, Appl. Phys. B: Lasers Opt. 68, 795 (1999).

${ }^{31}$ N. Iyi, K. Kitamura, Y. Yajima, S. Kimura, Y. Furukawa, and M. Sato, J. Solid State Chem. 118, 148 (1995).

${ }^{32}$ Y. Furukawa, K. Kitamura, S. Takekawa, K. Niwa, Y. Yajima, N. Iyi, I. Mnushkina, P. Guggenheim, and J. M. Martin, J. Cryst. Growth 211, 230 (2000).

${ }^{33}$ H. Cerva, P. Pongratz, and P. Skalicky, Philos. Mag. A 54, 199 (1986). 